\title{
Lung sounds in asbestos induced pulmonary disorders
}

\author{
P. Piirilä*, H. Lehtola*, A. Zitting*, L. Kivisaari\#, H. Koskinen*, R. Luukkonen*, S.P. Salo, \\ T. Vehmas ${ }^{*}$, H. Nordman*, A.R.A. Sovijärvi ${ }^{+}$
} Lung sounds in asbestos induced pulmonary disorders. P. Piirilä, H. Lehtola, A. Zitting, L.
Kivisaari, H. Koskinen, R. Luukkonen, S-P. Salo, T. Vehmas, H. Nordman, A.R.A. Sovijärvi. (C) ERS Journals Ltd 2000.

ABSTRACT: The aim of the study was to compare the lung sounds in patients with asbestos related pulmonary disorders with findings in high-resolution computed tomography (HRCT), and with lung function variables, in order to find out associations of acoustic changes with radiological fibrosis, emphysema or with pulmonary gas transfer functions.

Sixty-four patients with asbestos-related pleural disease, with or without pulmonary disease, were studied. Lung sound recording and analysis was carried out with a computerized lung sound analyser, and HRCT of the chest, as well as forced spirometry and diffusing capacity measurement were performed.

The fibrosis score correlated positively with the quartile frequencies of the power spectrum of lung sounds in inspiration ( 550$)$ and expiration ( 550$)$ and crackle count in inspiration, as well as negatively with diffusing capacity. When the patients with crackling sounds and significant fibrosis were excluded $(n=18)$, emphysema correlated negatively with expiratory quartile frequencies of the power spectrum, with $f 25$ and f50. Furthermore, diffusing capacity correlated with inspiratory $f 25$ and forced expiratory volume in one second with inspiratory $f 50$ when crackles and fibrosis were excluded.

Changes in lung sounds were significantly associated with radiologically verified abnormalities and gas transfer of pulmonary tissue. High sound frequencies were associated with fibrotic changes of the lung while low sound frequencies with pulmonary emphysema. Acoustic analysis gives complementary clinical information for evaluation of asbestos-related pulmonary disorders.

Eur Respir J 2000; 16: 901-908.

\author{
*Dept of Occupational Diseases, Finnish \\ Institute of Occupational Health, ${ }^{\#}$ Dept of \\ Radiology, and ${ }^{+}$Laboratory of Clinical \\ Physiology, Helsinki University Central \\ Hospital, Helsinki, Finland.
}

Correspondence: P. Piirilä, Helsinki University Hospital, Laboratory of Clinical Physiology, PL 360, 00029 HUS, Helsinki, Finland. Fax: 358947174018

Keywords: Asbestosis

emphysema

lung sounds

Received: March 72000

Accepted after revision August 32000

This study has been supported by the Finnish Work Environment Fund and Helsinki University Hospital grant TYH 0033 .
Lung sounds may reflect pathophysiological changes in the airways and pulmonary tissue. Earlier studies have suggested that the appearance of crackling lung sounds could be an early sign of pulmonary asbestosis $[1,2]$. MurPhy and SORENSEN [3] have found that the duration of asbestos exposure associated with auscultatory scoring of crackles and concomitantly with the decrease in pulmonary diffusing capacity. In asbestosis, the occurrence of crackles has been reported to correlate with radiological honeycombing of the lungs, histopathologically assessed severity of the disease [4] and the duration of asbestos exposure [1, 2, 4]. However, the conventional auscultation with a stethoscope can, according to different studies, reveal crackles in only $19-32 \%$ of asbestosexposed patients $[1-3,5]$. Eventual changes in frequency spectra of lung sounds in these conditions are not possible to be evaluated by ordinary auscultation. Thus, there is evidence that ordinary auscultation is not sensitive enough for assessing asbestos-induced pulmonary disorders.

Computerized lung sound analysis has become a new tool for the objective and automatic analysis of acoustic phenomena of the airways and lungs during breathing [6]. High-resolution computed tomography (CT) (HRCT) of the chest has become the reference method for the radiological diagnosis of pulmonary fibrosis and emphy- sema, and CT that for pleural abnormalities [7-9]. AL JARAD et al. [5] found that crackles could be found more often by sound analysis than by conventional pulmonary auscultation, and slight subpleural fibrotic changes could be distinguished in sound analysis in similar frequency as in HRCT. However, patients with asbestosis or other subpleural fibrosis do not always have crackling lung sounds.

Patients with asbestos exposure are often smokers. Therefore, when assessing functional impairment of asbestos induced pleural and pulmonary diseases, changes caused by airway obstruction and emphysema are to be distinguished. Differential analysis of lung sound changes due to emphysema or fibrosis components in patients with asbestos exposure is not available in the previous literature.

The aim of the study was to compare acoustical, radiological and pathophysiological characteristics of lungs in patients with asbestos-induced pulmonary disorders, frequently consisting of emphysema or fibrosis of pulmonary tissue, in order to find out characteristic lung sound patterns for emphysema and fibrosis in these patients. Lung sounds were analysed from samples of sound recordings with and without crackling lung sounds with computerized methods. Those were compared with findings in HRCT of the lungs, in flow/volume spirometry and in pulmonary diffusing capacity measurements. 


\section{Patients}

The first 64 consecutive male subjects of a screening study of $\sim 600$ asbestos-exposed individuals with pleural plaques living in southern Finland were studied with lung sound analysis, lung function tests, CT and HRCT at the Finnish Institute of Occupational Health. The anthropometric data on the patients are given in table 1. Fifty-five subjects were current or exsmokers, having smoked $30 \pm 5$ pack-yrs (mean $\pm \mathrm{SD})$. The duration of asbestos exposure was $22.4 \pm 13.3$ yrs (range: $2-49$ yrs). The asbestos exposure had started $39 \pm 10$ yrs before the present examinations. Spirometry was normal in 19 patients, 18 showed obstructive (forced expiratory volume in one second (FEV1)/forced vital capacity (FVC) $<88 \%$, peak expiratory flow (PEF) $<75 \%$, FEV $1<80 \%$ or maximal expiratory flow when $50 \%$ of FVC remains exhaled (MEF50) $<63 \%$ of predicted the value [10]), 11 restrictive (vital capacity (VC) or FVC $<80 \%$ pred [10]) and 16 combined, both obstructive and restrictive ventilatory function impairment. Four patients showed a significant reversibility in the bronchodilation test. Six patients had coronary heart disease, seven had essential hypertension, and two had chronic atrial fibrillation. No one had cardiac decompensation. Seven patients used inhaled steroids, seven ipratropium bromide, two salmeterol and four salbutamol inhalations.

The protocols have been approved by the institutional ethic board, and the informed written consent of the subjects was obtained.

\section{Methods \\ Lung sound recording and analysis methods}

Lung sound recording and analysis was carried out with a computerized lung sound analyser (Helsinki Lung Sound Analyzer (HeLSA)) [11]. The lung sounds were recorded on the back basal area of the right lung, $\sim 7 \mathrm{~cm}$ below the lower margin of the scapula and $\sim 5 \mathrm{~cm}$ from the midline, when the patient was in sitting position. The inspiratory and expiratory flow was controlled by visual autofeedback using a flow monitor to obtain a tidal breathing pattern with a peak tidal flow of $\sim 1.25 \mathrm{~L} \cdot \mathrm{s}^{-1}[12]$. The nose was closed with a clamp. The recording was started by a $10 \mathrm{~s}$ breath holding for recording and monitoring the individual background noise, followed by recording of airflow and lung sound during 7-10 consecutive inspirations and expirations. The sound analysis included: 1) inspiratory and expiratory peak tidal flow; 2) crackle count per inspiratory and expiratory cycles; 3 ) measurement of the timing of crackles from phonopneumograms: starting, duration and end point of crackling as a percentage of total duration of inspiration or expiration [13]; and 4) time-expanded waveform for the duration of the initial deflection (IDW), the two-cycle duration (2CD) determined as the time from the beginning of crackle to the point where the crackle has completed two cycles [14], and the largest deflection width (LDW), i.e. the deflection with the largest amplitude [15]. The crackles were detected automatically by the software validated earlier [11]. The automatically detected crackles were verified visually from the time-expanded waveform display by using the crackle criteria of MURPHY et al. [14] and VANNUCINI et al. [16]. The lung sound recordings
Table 1. - Anthropometric data and values of lung function parameters. FVC (forced vital capacity), FEV 1 (forced expiratory volume in one second), MEF50 (maximal expiratory flow at the level when $50 \%$ of FVC remains exhaled), MMEF (maximal mid-expiratory flow), the diffusing capacity and total capacity

\begin{tabular}{lc}
\hline Anthropometric data & \\
\hline Age yrs & $61 \pm 7(45-80)$ \\
Weight kg & $81 \pm 11(54-106)$ \\
Height cm & $173 \pm 7(153-190)$ \\
Body mass index & $26.92 \pm 3.39(20-35)$ \\
Lung function results & \\
FVC L & $3.84 \pm 0.99(1.97-6.11)$ \\
FVC \% pred & $84.6 \pm 18.85(50.0-130.0)$ \\
FEV1 L & $2.80 \pm 0.89(1.25-4.76)$ \\
FEV1 \% pred & $76.2 \pm 21.1(37.0-119.0)$ \\
MEF50 L-s ${ }^{-1}$ & $2.83 \pm 1.60(0.41-7.13)$ \\
MEF50 \% pred & $58.9 \pm 32.3(9.0-142.0)$ \\
MMEF L-s ${ }^{-1}$ & $2.19 \pm 1.22(0.34-5.66)$ \\
MMEF \% pred & $53.0 \pm 27.4(10.0-122.0)$ \\
Diffusing capacity \% pred & $76.1 \pm 20.2(26.5-119.0)$ \\
Specific diffusing capacity \% pred & $89.8 \pm 22.9(29.9-151.0)$ \\
Total lung capacity L & $5.82 \pm 1.23(3.10-8.54)$ \\
Total lung capacity \% pred & $82.6 \pm 14.7(48.1-123.0)$ \\
\hline
\end{tabular}

Data presented as mean \pm SD (range). FVC: forced vital capacity; FEV1: forced expiratory volume in one second; MEF50: maximal expiratory flow when $50 \%$ of FVC remains exhaled; MMEF: maximal mid-expiratory flow; \% pred: percentage of predicted value.

were also studied with a wheezing detector of the HeLSA system [17], and the durations and frequencies of wheezing sounds were measured.

The fast Fourier transform (FFT) spectrum analysis was performed using Hanning-windowed 1,024-point FFT. The sample rate of all recordings was $6 \mathrm{kHz}$. From the recorded lung sound the following parameters were automatically calculated as an average over the whole recorded sample, inspirations and expirations separately: the frequency of maximal amplitude in the spectrum ( $\left.f_{\max }\right)$, root mean square; the amplitude of the sound of the power spectrum (RMS) [12], the (first, second and third) quartile frequencies in the power spectrum $(f 75, f 50, f 25)[12,18]$.

\section{Environmental noise measurements}

The frequency characteristics (mean $\pm \mathrm{SD}$ ) of the individual background during breath holding were as follows: $f_{\max } 141.37 \pm 63 \mathrm{~Hz}, f 25 \quad 110.23 \pm 12.9 \mathrm{~Hz}, f_{50} \quad 179 \pm 28 \mathrm{~Hz}$ and $f 75249 \pm 31 \mathrm{~Hz}$; a peak at about $1 \mathrm{kHz}$ was distinguished in all recordings coming from the computer. The noise level of the recording room was $37-40 \mathrm{~dB}$ (according to human hearing threshold) and linear 57-60 dB measured with Bruel \& Kjaer Type 2231 Modular Precision Sound Level Meter Integrating SLM Module BZ 7100 (Bruel \& Kjaer, Naerum, Denmark).

\section{Radiological methods}

All patients underwent chest CT (Picker PQ 2000, Picker, USA) performed in two phases. 1) Unenhanced spiral CT $(140 \mathrm{kV}, 125 \mathrm{~mA}$, collimation $10 \mathrm{~mm}$, exposure time $1.5 \mathrm{~s}$, pitch factor 1.5 , increment $10 \mathrm{~mm}$, algorithm "standard"). The images covered an area from the lung apexes to the most caudal pleural extensions. 2) HRCT 


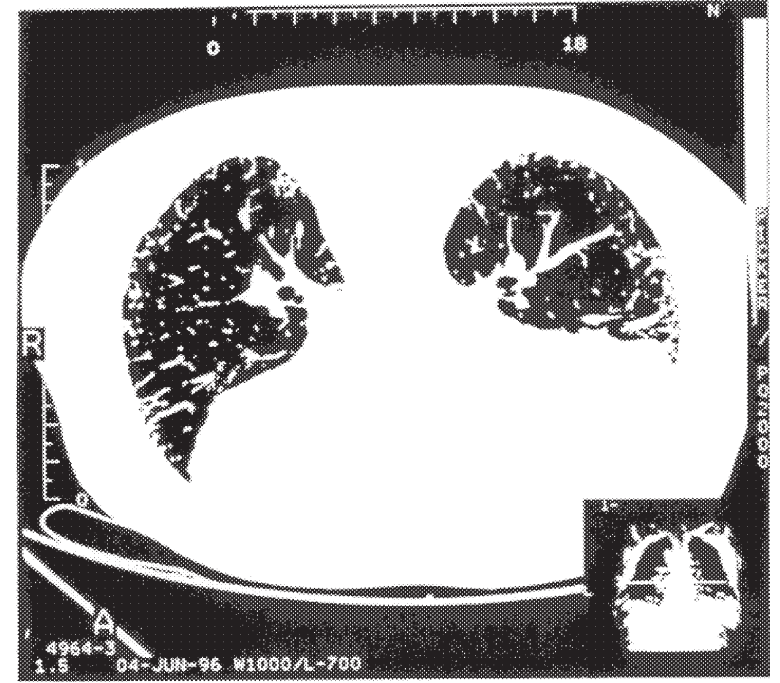

Fig. 1. - The high-resolution computed tomography (HRCT) finding of a patient with asbestosis: a 62-yr-old nonsmoking male exposed to asbestos 1947-1983 working as a timberman in construction work. In the HRCT both-sided subpleural abnormalities are seen consistent with interstitial pulmonary fibrosis.

$(130 \mathrm{kV}, 200 \mathrm{~mA}$, collimation $1.5 \mathrm{~mm}$, exposure time $1.5 \mathrm{~s}$, algorithm "sharp"). The following $(1.5 \mathrm{~mm})$ slices were taken from the chest: 1) at the level of the carina; 2) at the level of the dome of the higher diaphragm; 3) halfway between slices 1 and 2; and 4) halfway between slice 2 and the lower costophrenic angle (fig. 1). The window level (WL) and width (WW) were set at 700/1000 for lung and 40/400 for soft tissue.

The classification of the radiological findings of pulmonary tissue and pleura was developed by radiologists and based on the classifications recommended earlier [7, $19,20]$. A semiquantitative and a more detailed classification were used. The semiquantitative scoring of HRCT findings indicating interstitial lung fibrosis in both lungs was an arbitrary scale from 0 (no changes), to five (severe) with five subcategories: $0 / 1,1 / 2,2 / 3,3 / 4$ and $4 / 5$. In the detailed classification subpleural curvilinear opacities, subpleural perpendicular lines, "other shadows suggesting fibrosis" and honeycombing were classified in both lungs separately with a similar scale from $0-5$ without subcategories, as well as signs of centrilobular, paraseptal and panlobular emphysema and bullae. The average thickness of pleural thickenings was classified: $0,1=<5 \mathrm{~mm}, 2=5-$ $10 \mathrm{~mm}, 3=>10 \mathrm{~mm}$. The average extent of the pleural thickenings was evaluated in square centimetres. The calcification of pleural thickenings was classified $0=$ no, $1=$ sparse, $2=$ a considerable part of the pleural thickening, $3=$ nearly all. Pleural adherences (fibrotic strands extending from the pleura into the lung parenchyma), adherences of the diaphragms or sinuses, in other locations than the diaphragm or the costophrenic angles, converging adherences, i.e. so-called "crows feet" adherences, as well as thickened bronchial walls, bronchiectases, or signs of other parenchymal disorders were classified $0-3$.

\section{Validation of high-resolution computed tomography scoring}

Three radiologists classified the HRCT findings independently. For the evaluations of the HRCT of pul- monary fibrosis, emphysema and pleural thickenings, the weighted Kappa coefficient varied between radiologists: A. Zitting and L. Kivisaari 0.49-0.68, between A. Zitting and T. Vehmas $0.38-0.74$, between L. Kivisaari and T. Vehmas $0.23-0.75$. The median of the scores evaluated by the three radiologists was used to compare the HRCT finding with the lung function, lung sound measurements, smoking and asbestos exposure history.

\section{Lung function studies}

Flow/volume spirometry was performed with a rollingseal spirometer (Mijnhardt Vicatest 3; Mijnhardt BV, Bunnik, the Netherlands) connected to a microcomputer (Medikro MR-3, Medikro, Kuopio, Finland), using the reference values of VILJANEN et al. [10]. The flow/volume curve was formed with the envelope method from curves obtained from at least three successive forced expiratory breathing manoeuvres by using the standards of the European Respiratory Society (ERS) [21]. The following parameters were measured: FVC, FEV1 and MEF50. Also the FEV1/FVC ratio was calculated. The single breath diffusing capacity for carbon monoxide ( $D \mathrm{~L}, \mathrm{CO})$, specific diffusing capacity ( $D \mathrm{~L}, \mathrm{CO} / \mathrm{VA})$ and the total lung capacity (TLC) with the single-breath helium-dilution method were measured by using a Masterlab Transfer or a Compact lab Transfer device (Erich Jaeger, Würzburg, Germany); the mean values from at least two successful measurements were recorded. The spirometric variables, as well as the $D \mathrm{~L}, \mathrm{CO}$ and the $D \mathrm{~L}, \mathrm{CO} / \mathrm{VA}$ were treated as percentages of the predicted value [10].

\section{Statistical methods}

For statistical analysis, the lung sound parameters from the right lung were used. The lung sound parameters were compared with the semiquantitative score for fibrosis evaluated for both lungs. In emphysema, scores pointing to centrilobular, paraseptal, panlobular and bullose emphysema from the right lung were summed up, when fibrosis was excluded. The counts of panlobular and centrilobular emphysema representing diffuse emphysema were summed up when emphysema was compared with the lung sound parameters. The scoring of pleural adhesions (adherences, converging adherences and thickness of the underlying pleura) was summed up.

Spearman's rank correlation was used to correlate the findings in HRCT and lung sound, asbestos exposure, smoking and lung function variables; continuous variables (sound frequencies and intensities) were tested with Pearson's correlation (SAS, version 612). The p-values $<0.05$ were considered significant.

\section{Results}

\section{General}

The mean peak inspiratory flow during the recording was $1.10 \pm 0.23 \mathrm{~L} \cdot \mathrm{s}^{-1}$ and peak expiratory flow $1.05 \pm 0.23$ $\mathrm{L} \cdot \mathrm{s}^{-1}$. Crackling sounds were detected in $65 \%$ of the subjects during inspiration and in $22 \%$ during expiration. Crackles were found in 43 patients in sound analysis (fig. 2 ), whereas the clinicians had indicated 28 patients having cracking sounds, which is significantly less $(p<0.001$, McNemar's test). Most crackles were of short duration; the mean IDW in inspiration was $0.91 \mathrm{~ms}$, and LDW $2.20 \mathrm{~ms}$ 
(table 2). There were no associations of HRCT findings or lung functions with IDW, 2CD or LDW.

\section{Association of lung sounds with fibrosis}

The semiquantitative fibrosis score was $\geq 2$ in eight patients. The detailed scores for both lungs were compared to assess side differences. The score was the same for both lungs for subpleural curvilinear opacities in $89 \%$, for subpleural perpendicular lines in $92 \%$, "other shadows suggesting fibrosis" in $86 \%$ and for honeycombing in 100\% of the cases.

The crackle count in inspiration and expiration correlated with the semiquantitative fibrosis score (table 3 ). The crackles in fibrosis occurred late in the respiratory cycle; there was a positive correlation with the timing parameters; start and end of crackling in the inspiratory and the expiratory cycle. Also the duration of the crackling percentage of inspiratory cycle correlated with the fibrosis score in inspiration (table 3 ).

The semiquantitative HRCT fibrosis score correlated positively with the quartile frequencies of the FFT spectrum in inspiration and in expiration (table 4; fig. 3). With the condition, the emphysema score $=0$ ("no emphysema") the correlation with frequency parameters ( $f 50$ and $f 75$ inspiration) was also significant (table 4). With the condition that the crackle counts in inspiration and expiration were 0 and the emphysema score $=0(n=15)$ the correlations between the fibrosis score and the quartile frequencies were not significant.

\section{Association of lung sounds with pleural thickenings}

In the CT scan, the mean \pm SD extent of pleural thickenings was $78 \pm 51 \mathrm{~cm}^{2}$ (range $10-200 \mathrm{~cm}^{2}$ ). The extent of pleural thickenings and the average thickness of pleural thickenings correlated with crackle count, start and end in inspiration when the fibrosis score was $<1$ (table 3). Ad-

Table 2. - The characteristics of the lung sound variables in all patients $(n=64)$.

\begin{tabular}{lc}
\hline Sound variables & \\
\hline$f_{\text {max in inspiration } \mathrm{Hz}}$ & $141.0 \pm 29.8(100.0-199.0)$ \\
$f_{\text {max in expiration } \mathrm{Hz}}$ & $116.9 \pm 32.2(82.0-252.0)$ \\
$f 25$ in inspiration $\mathrm{Hz}$ & $131.9 \pm 16.3(100.0-176.0)$ \\
$f 25$ in expiration $\mathrm{Hz}$ & $111.2 \pm 10.6(94-158)$ \\
$f 50$ in inspiration $\mathrm{Hz}$ & $190.3 \pm 26.6(135.0-270.0)$ \\
$f 50$ in expiration $\mathrm{Hz}$ & $158.4 \pm 22.4(123.0-246.0)$ \\
$f 75$ in inspiration $\mathrm{Hz}$ & $278.0 \pm 53.5(205.0-457.0)$ \\
f75 in expiration $\mathrm{Hz}$ & $235.6 \pm 34.8(176.0-375.0)$ \\
Crackle count in inspiratory cycle & $1.19 \pm 2.18(0-9.83)$ \\
Crackle count in expiratory cycle & $0.47 \pm 1.31(0-8.9)$ \\
IDW in inspiration ms & $0.91 \pm 0.16(0.68-1.32)$ \\
IDW in expiration ms* & $0.90 \pm 0.34(0.54-1.55)$ \\
LDW in inspiration ms & \\
LDW in expiration ms* & $2.20 \pm 0.42(1.36-3.33)$ \\
2CD in inspiration ms & $1.87 \pm 0.42(1.24-2.94)$ \\
2CD in expiration ms* & $8.25 \pm 0.94(5.35-10.79)$ \\
& $7.52 \pm 1.52(5.79-10.84)$ \\
\hline
\end{tabular}

Data presented as mean $\pm \mathrm{SD}$ (range). fmax: frequency of maximal intensity of the power spectrum; $f 25, f 50$ and $f 75$ : the quartile frequencies of the power spectrum; IDW: initial deflection width; LDW: the largest deflection width, 2CD: two-cycle duration; ${ }^{\#}: \mathrm{n}=41 ; *: \mathrm{n}=13$. herence scores did not correlate with the sound parameters.

\section{Association of lung sounds with emphysema}

The additive emphysema score was $\geq 2$ in nine patients. Emphysema correlated with RMS value during expiration $(\mathrm{rS}=0.0264 ; \mathrm{p}=0.035)$. There was a positive correlation with crackling duration in expiration (table 3), otherwise emphysema did not correlate with the crackle parameters. When both significant fibrosis and the inspiratory and expiratory crackles were excluded, there was a significant negative correlation of the emphysema score with the sound parameters in expiration, $f 25$ and $f 50$ expiration (table 4).

Association of lung sounds with lung function tests, body mass index and asbestos exposure

There was a significant negative correlation of crackle count with DL,CO (rS=-0.334; $\mathrm{p}=0.0075)$ in the whole
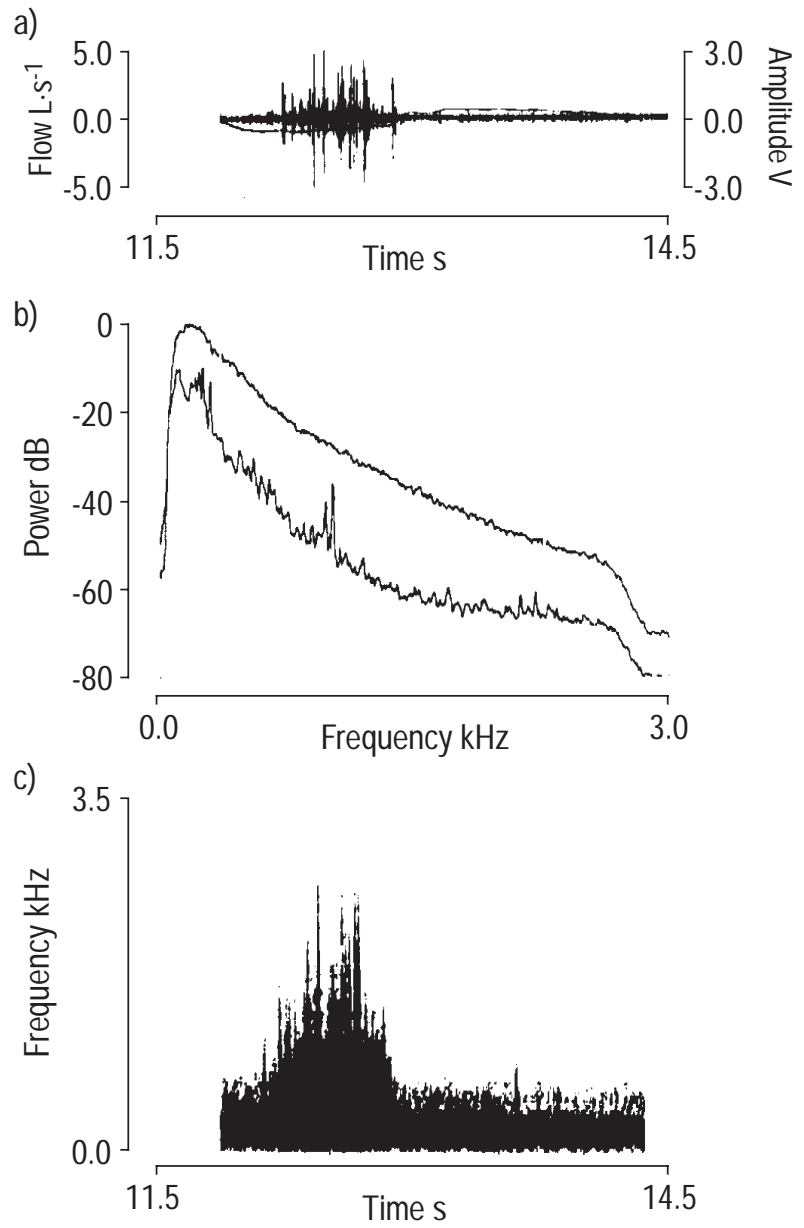

Fig. 2. - The lung sound analysis of the patient presented in figure 1. a) The phonopneumogram of one inspiration and expiration showing inspiratory crackle sounds as sharp peaks. The inspiration is presented with negative flow and expiration with a positive air flow. b) An averaged power spectrum from 11 respiratory cycles. The upper curve represents the inspiratory and the lower curve the expiratory power spectrum. The inspiratory spectrum is high in spectral contents because of crackling sounds. c) The sonogram spectrum from the same sound cut as the two figures above. The inspiratory crackling sounds are visualized as high-frequency peaks. 
Table 3. - Correlations of the high-resolution computed tomography finding with crackle count and timing parameters.

\begin{tabular}{|c|c|c|c|c|c|c|c|c|c|}
\hline & \multirow{2}{*}{ Subjects $n$} & \multicolumn{2}{|c|}{ Crackle count } & \multicolumn{2}{|c|}{ Crackling start } & \multicolumn{2}{|c|}{ Crackling end } & \multicolumn{2}{|c|}{ Crackling duration } \\
\hline & & Inspiration & Expiration & Inspiration & Expiration & Inspiration & Expiration & Inspiration & Expiration \\
\hline Fibrosis score & 64 & $\begin{array}{c}0.625 \\
(0.0001)\end{array}$ & $\begin{array}{c}0.313 \\
(0.012)\end{array}$ & $\begin{array}{c}0.403 \\
(0.001)\end{array}$ & $\begin{array}{c}0.248 \\
(0.049)\end{array}$ & $\begin{array}{c}0.536 \\
(0.0001)\end{array}$ & $\begin{array}{c}0.287 \\
(0.021)\end{array}$ & $\begin{array}{c}0.489 \\
(0.0001)\end{array}$ & $\begin{array}{c}0.049 \\
(0.698)\end{array}$ \\
\hline Fibrosis score $^{+}$ & 42 & $\begin{array}{c}(0.00017 \\
0.617 \\
(0.0001)\end{array}$ & $\begin{array}{c}(0.012) \\
0.174 \\
(0.270)\end{array}$ & $\begin{array}{c}(0.001) \\
0.570 \\
(0.0001)\end{array}$ & $\begin{array}{c}(0.049) \\
0.138 \\
(0.385)\end{array}$ & $\begin{array}{c}(0.6003) \\
0.603 \\
(0.0001)\end{array}$ & $\begin{array}{c}(0.021) \\
0.197 \\
(0.212)\end{array}$ & $\begin{array}{c}(0.0001) \\
0.464 \\
(0.0019)\end{array}$ & $\begin{array}{c}(0.098) \\
\text { ND }\end{array}$ \\
\hline Emphysema score & 64 & $\begin{array}{c}0.258 \\
(0.039)\end{array}$ & $\begin{array}{c}0.206 \\
(0.103)\end{array}$ & $\begin{array}{l}-0.110 \\
(0.386)\end{array}$ & $\begin{array}{c}0.166 \\
(0.189)\end{array}$ & $\begin{array}{c}0.037 \\
(0.771)\end{array}$ & $\begin{array}{c}0.198 \\
(0.117)\end{array}$ & $\begin{array}{c}0.174 \\
(0.170)\end{array}$ & $\begin{array}{c}0.276 \\
(0.027)\end{array}$ \\
\hline Emphysema score $^{\#}$ & 41 & $\begin{array}{c}0.159 \\
(0.328)\end{array}$ & $\begin{array}{l}-0.029 \\
(0.858)\end{array}$ & $\begin{array}{c}0.040 \\
(0.805)\end{array}$ & $\begin{array}{c}-0.039 \\
(0.811)\end{array}$ & $\begin{array}{c}0.087 \\
(0.593)\end{array}$ & $\begin{array}{c}-0.004 \\
(0.979)\end{array}$ & $\begin{array}{c}0.083 \\
(0.611)\end{array}$ & $\begin{array}{c}0.357 \\
(0.022)\end{array}$ \\
\hline Extent $^{+, \#}$ & 29 & $\begin{array}{c}0.560 \\
(0.0016)\end{array}$ & $\begin{array}{c}0.056 \\
(0.773)\end{array}$ & $\begin{array}{c}0.552 \\
(0.0019)\end{array}$ & $\begin{array}{c}0.052 \\
(0.787)\end{array}$ & $\begin{array}{c}0.556 \\
(0.0017)\end{array}$ & $\begin{array}{c}0.160 \\
(0.406)\end{array}$ & $\begin{array}{c}0.240 \\
(0.211)\end{array}$ & ND \\
\hline Thickness ${ }^{+, \#}$ & 29 & $\begin{array}{c}0.541 \\
(0.0024)\end{array}$ & $\begin{array}{l}-0.033 \\
(0.864)\end{array}$ & $\begin{array}{c}0.591 \\
(0.0007)\end{array}$ & $\begin{array}{l}-0.107 \\
(0.580)\end{array}$ & $\begin{array}{c}0.582 \\
(0.0009)\end{array}$ & $\begin{array}{l}-0.167 \\
(0.385)\end{array}$ & $\begin{array}{c}0.321 \\
(0.089)\end{array}$ & ND \\
\hline Bronchiectasis score ${ }^{+, \#}$ & 30 & $\begin{array}{c}0.338 \\
(0.068)\end{array}$ & $\begin{array}{c}0.479 \\
(0.0074)\end{array}$ & $\begin{array}{c}0.166 \\
(0.381)\end{array}$ & $\begin{array}{c}0.380 \\
(0.038)\end{array}$ & $\begin{array}{c}0.273 \\
(0.145)\end{array}$ & $\begin{array}{c}0.417 \\
(0.0217)\end{array}$ & $\begin{array}{c}0.420 \\
(0.0209)\end{array}$ & ND \\
\hline
\end{tabular}

Data are presented as Spearman correlation coefficient with p-value in parentheses. Extent: extent of pleural thickenings; thickness: average thickness of pleural plaques; ${ }^{+}$: emphysema score $=0$; ${ }^{\#}$ : fibrosis score $<1$; ND: not determined.

patient material (fig. 4). Expiratory f25 ( $\mathrm{rS}=-0.299 ; \mathrm{p}=$ $0.0165)$ and $f 50(\mathrm{rS}=-0.270 ; \mathrm{p}=0.0305)$ correlated negatively with $\mathrm{FVC}$, and inspiratory $f 25(\mathrm{rS}=0.340 ; \mathrm{p}=0.006)$ and $f 50(\mathrm{rS}=0.271 ; \mathrm{p}=0.031)$ with $\mathrm{FEV} 1 / \mathrm{FVC}$. After exclusion of recordings with crackle sounds and significant fibrosis, the following correlations with inspiratory sound parameters were found. FVC correlated positively with inspiratory $f 75$, and FEV 1 with $f 25, f 50$ and $f 75$. MEF50 correlated both with $f 25, f 50$ and $f 75$ and $\mathrm{FEV} 1 / \mathrm{FVC}$ with f25 (table 5). DL,CO correlated positively with inspiratory f25 (fig. 5), RMS and fmax. After exclusion of emphysema, there was no correlation of FVC and the quartile frequencies, but there were correlations of FEV1 and MEF50 with the inspiratory quartile frequencies (table 5; fig.6), and FEV\% correlated only with inspiratory $f 25$.

There was no correlation of sound parameters with body-mass index, nor did we find association between asbestos exposure and the lung sound parameters.

\section{Wheezes and squawks}

Wheezing sounds were detected in the lung sound recording of seven patients only, comprising five

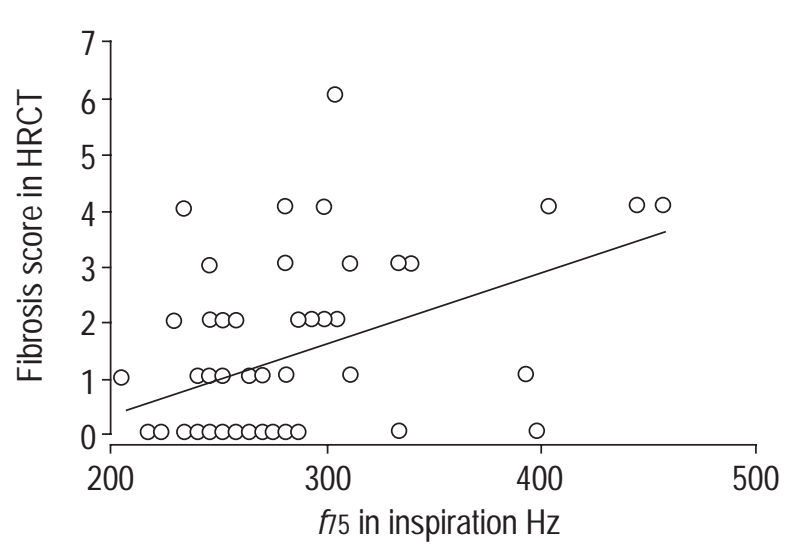

Fig. 3. - Correlation of semiquantitative fibrosis score in highresolution computed tomography and upper quartile frequency of the power spectrum $(f 75)$ in inspiration in all patients $(n=63 ; r s=0.435$; $\mathrm{p}=0.004)$. inspiratory and 11 expiratory wheezes, with the duration of $73.2 \pm 29.3 \mathrm{~ms}(\operatorname{mean} \pm \mathrm{SD})$, range $70-117,500 \mathrm{~ms}$, the frequency of $199 \pm 100 \mathrm{~Hz}$, range 93-375 Hz. Five squawks, defined as continuous sounds with the duration below $100 \mathrm{~ms}$, were found in four patients, four of them inspiratory.

\section{Discussion}

Inspiratory crackling lung sounds are typical for asbestosis [22], probably due to stiffened peripheral airways, lowered pulmonary compliance, and destruction of alveoli by fibrosis. In the present material, the pulmonary fibrosis detected in HRCT showed a significant positive correlation with frequencies of lung sounds, as evidenced also in earlier studies $[1,23]$. The relatively high average frequencies of the lung sounds can be explained here by the presence of crackles which contain high frequency components $[1,6]$. When the recordings with crackles were excluded, there was no correlation between the HRCT finding and the frequency parameters. Therefore, it is likely that the adventitious sounds markedly

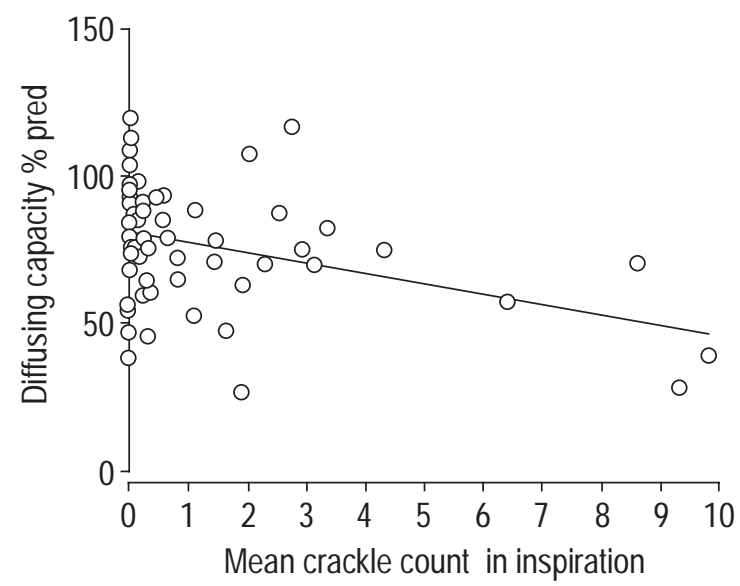

Fig. 4. - Correlation of single-breath diffusing capacity for carbon monoxide and crackle count during inspiration in the whole patient material. $r S=-0.334 ; p=0.0075$; and $n=63$. 
Table 4. - Correlations of emphysema and fibrosis score with lung sound variables.

\begin{tabular}{lccccccr}
\hline & \multirow{2}{*}{ Subject $\mathrm{n}$} & \multicolumn{2}{c}{$f 25$} & \multicolumn{2}{c}{$f 50$} & \multicolumn{2}{c}{$f 75$} \\
\cline { 3 - 8 } & & Inspiration & Expiration & Inspiration & Expiration & \multicolumn{1}{c}{ Inspiration } & \multicolumn{1}{c}{ Expiration } \\
\hline Fibrosis score & 64 & $0.194(0.125)$ & $0.350(0.0046)$ & $0.366(0.0029)$ & $0.406(0.0009)$ & $0.434(0.0003)$ & $0.316(0.011)$ \\
Fibrosis score $^{+}$ & 42 & $0.195(0.217)$ & $0.212(0.178)$ & $0.306(0.049)$ & $0.243(0.122)$ & $0.351(0.023)$ & $0.189(0.232)$ \\
Emphysema score $^{\#, \S}$ & 18 & -0.3930 .107 & $-0.478(0.045)$ & $-0.391(0.109)$ & $-0.482(0.043)$ & $-0.304(0.220)$ & $-0.276(0.267)$ \\
\hline
\end{tabular}

Data are presented as Spearman correlation coefficient with p-value in parentheses. $f 25, f 50, f 75$ : quartile frequencies of the power spectrum; ${ }^{+}$: emphysema score $=0 ;{ }^{\#}$ : fibrosis score $<1 ;{ }^{\text {}}$ : crackles $=0$.

contribute to the high frequency spectrum observed in fibrosis.

In the present patients, the extent and thickness of the pleural thickenings correlated with inspiratory crackle count, as well as with the start and end of crackling in inspiration. AL JARAD et al. [23] have documented crackles in asbestos-related pleural disease in $41 \%$ of their patients. The present observations show that pleural abnormalities tend to cause crackling sounds in the absence of signs of subpleural fibrosis. The characteristics of the chest wall did not influence on the lung sounds, which is in accordance with some earlier studies [24].

It was found that emphysema [25] detected in HRCT was associated with low sound frequencies when the crackling sounds were excluded. This suits the transmission theories; due to tissue destruction, the average density of lung tissue is reduced. This could affect the transmission of lung sounds, and consequently, the frequency distribution of lung sounds detected at the chest wall would become lower [26]. The present results support the findings of MALMBERG et al. [27] who found that the $f_{50}$ values were lower in chronic obstructive pulmonary disease (COPD) than in normal subjects, and correlated weakly with specific diffusing capacity, indicating that the changes in inspiratory sound would be affected by the degree of emphysema. However, they screened emphysema only by diffusing capacity values; no HRCT measurements were performed.

One new finding, as far as the authors' know, was the association of expiratory crackling with emphysema. The expiratory crackling may derive from chronic obstructive pulmonary disease combined with emphysema [13]. Whether emphysema changes per se may produce crackling sounds, warrants further studies. A correlation was also found between RMS and the HRCT findings of emphysema during expiration. The attenuated breath sounds in emphysema have been explained by airflow limitation [28, 29]. Earlier studies [29] have shown that the RMS value from the power spectrum do not differ between COPD and healthy individuals in standardized air flow.

In the patients without crackling sounds, the positive correlation of the inspiratory quartile frequencies with parameters derived from the expiratory flow/volume curve might be thought to be due to obstruction, because irreversible airway obstruction was found in about one half of the patients. However, it has been pointed out earlier that the severity of obstruction has a positive relationship with the quartile frequencies [30]. Therefore, in fibrosis, the changes in quartile frequencies might reflect the degree of the disease. The mechanisms of these changes may be decreased sound transmission in fibrotic tissue, reflecting changes especially in $f 50$ and $f 75$ [6]. The results suggest that slight fibrotic changes may be of importance especially because the changes in sound also correlated with diffusing capacity.

A semiquantitative scoring of abnormalities indicating interstitial lung fibrosis has proved useful in classifying HRCT findings [7]. In the present study, the semiquantitative scoring of fibrosis was done for both lungs, because usually the fibrotic changes in asbestosis are bilateral. When the scoring of different fibrosis types were compared between the lungs, there were only minor differences.

MuRPHY [3] and SHIRAI et al. [1] have found a relationship between crackle count and asbestos exposure.

Table 5. - The correlations of lung functions with the sound parameters, the quartile frequencies of the power spectrum $\left(f 25, f_{50}, f_{55}\right)$ and maximal frequency ( $\left.f_{\max }\right)$ and intensity (root mean square (RMS)) at inspiration when recordings with crackles, and emphysema and fibrosis was excluded.

\begin{tabular}{|c|c|c|c|c|c|}
\hline & $f \max$ & $f_{25}$ & $f 50$ & $f 75$ & RMS \\
\hline \multicolumn{6}{|c|}{ Emphysema excluded $n=15$} \\
\hline FEV ${ }^{*}$ & $0.289(0.296)$ & $0.560(0.234)$ & $0.655(0.008)$ & $0.640(0.010)$ & $0.231(0.408)$ \\
\hline MEF50 & $0.283(0.307)$ & $0.539(0.038)$ & $0.595(0.019)$ & $0.552(0.033)$ & $0.418(0.121)$ \\
\hline FEV1/FVC & $0.439(0.102)$ & $0.568(0.027)$ & $0.458(0.086)$ & $0.292(0.291)$ & $0.176(0.530)$ \\
\hline \multicolumn{6}{|c|}{ Fibrosis excluded $n=18$} \\
\hline FVC $^{*}$ & $0.175(0.487)$ & $0.282(0.256)$ & $0.418(0.084)$ & $0.477(0.046)$ & $0.103(0.683)$ \\
\hline FEV $1 *$ & $0.284(0.253)$ & $0.542(0.020)$ & $0.640(0.004)$ & $0.680(0.0019)$ & $0.238(0.342)$ \\
\hline MEF50* & $0.171(0.498)$ & $0.474(0.047)$ & $0.522(0.026)$ & $0.540(0.021)$ & $0.285(0.251)$ \\
\hline FEV1/FVC & $0.304(0.220)$ & $0.542(0.020)$ & $0.545(0.058)$ & $0.357(0.145)$ & $0.230(0.359)$ \\
\hline Diffusing capacity* & $0.529(0.024)$ & $0.473(0.047)$ & $0.392(0.108)$ & $0.237(0.344)$ & $0.481(0.043)$ \\
\hline
\end{tabular}

Data are presented as Spearman correlation coefficient with p-value in parentheses. FEV1: forced expiratory volume in one second; FVC: forced vital capacity; MEF50: maximal expiratory flow when $50 \%$ of FVC remains to be exhaled; *: statistics calculated from percentage of predicted value. 


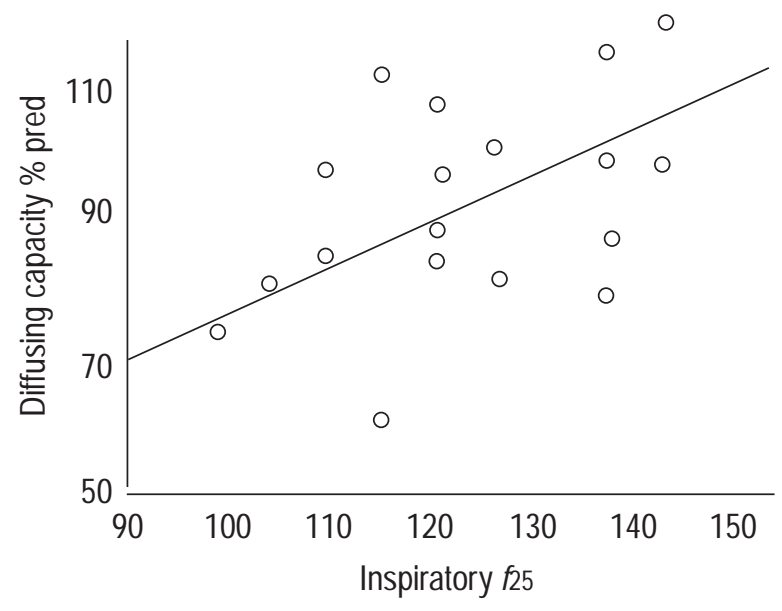

Fig. 5. - Correlation of inspiratory third quartile frequency of the power spectrum $(f 25)$ and diffusing capacity, when patients with fibrosis and crackles were excluded. $r S=0.473 ; p=0.047$ and $n=18$.

This result could not be repeated in the present material, possibly due to the smaller patient material.

The inspiratory and expiratory flow was standardized with visual monitoring and teaching of a regular breathing pattern, which does not totally exclude subjective variations. However, the peak inspiratory or expiratory flow rate did not correlate with the sound frequency parameters, so it can be assumed that the breathing pattern did not essentially influence the frequency parameters in the present patient material.

Out of 64 patients only 11 had short solitary wheezing lung sounds, being usually expiratory and low by their frequency contents. Therefore, it is believed that the occurrence of wheezing sounds has not influenced sound spectral variables significantly in these patients.

In conclusion, the frequency distribution of lung sounds as well as the number and timing of crackles in the respiratory cycles associated significantly with interstitial lung fibrosis revealed by HRCT scoring in asbestos-exposed subjects. The occurrence of inspiratory crackles and high frequency components in lung sounds was typical for fibrosis, whereas for emphysema component, there was a

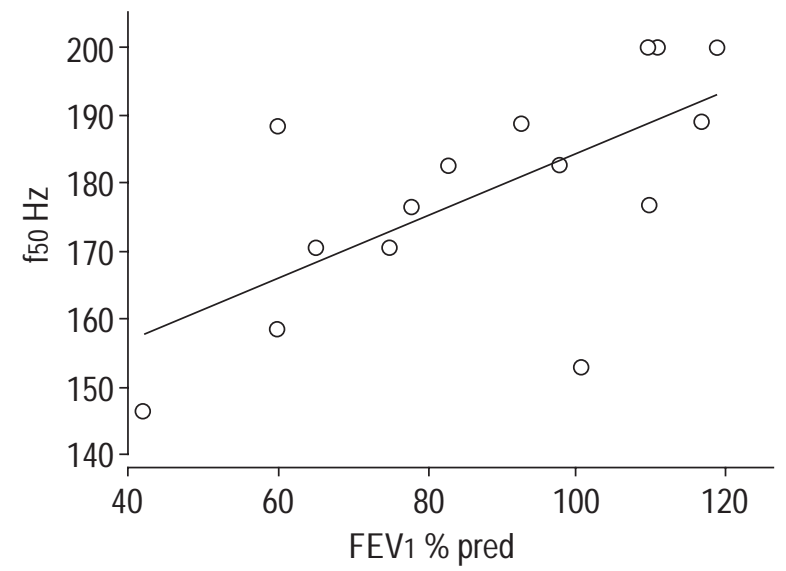

Fig. 6. - Correlation of mid quartile frequencies of the power spectrum $(f 50)$ and forced expiratory flow in one second (FEV1) when the patients with crackling sounds and emphysema were excluded. rs $=0.635$; $\mathrm{p}=0.0081 ; \mathrm{n}=15$. significant tendency to lower breath sound frequencies and occurrence of expiratory crackles. Crackle count was negatively associated with pulmonary diffusing capacity in asbestos-exposed subjects. The results also indicated changes in the frequency spectra, not associated with crackling lung sounds, both in pulmonary fibrosis and emphysema, probably due to changes in the sound transmission of the chest. The lung sound analysis gives complementary information for evaluation of asbestosrelated pulmonary disorders, and for differentiation of fibrosis and emphysema components in these diseases.

The question as to whether lung sound analysis would be a useful method for screening asbestos-exposed subjects needs further study including healthy controls for assessment of the sensitivity and specificity of lung sound analysis in the detection of asbestos-related pulmonary disorders.

\footnotetext{
Acknowledgements. The authors wish to thank T. Kaustia for revising the manuscript, $M$. Kämppi for the drawings and P. Ylöstalo for preliminary statistical work.
}

\section{References}

1. Shirai F, Kudoh S, Shibuya A, Sada K, Mikami R. Crackles in asbestos workers: auscultation and lung sound analysis. Br J Dis Chest 1981; 75: 386-396.

2. Mulphy RLH, Gaensler EA, Holford SK, Del Bono EA, Epler G. Crackles in the early detection of asbestosis. $\mathrm{Am}$ Rev Respir Dis 1984; 129: 375-379.

3. Murphy RLH, Sorensen K. Chest auscultation in the diagnosis of pulmonary asbestosis. $J$ Occ Med 1973; 15: 272-276.

4. Epler GR, Carrington CB, Gaensler EA. Crackles (rales) in the interstitial pulmonary diseases. Chest 1978; 73 : 333-339.

5. Al Jarad N, Strickland B, Bothamley G, Lock S, LoganSinclair R, Rudd RM. Diagnosis of asbestosis by a timeexpanded wave form analysis, auscultation and high resolution computed tomography: a comparative study. Thorax 1993; 48: 347-353.

6. Pasterkamp H, Kraman S, Wodicka R. Respiratory sounds. Advances beyond the stethoscope. Am J Respir Crit Care Med 1997; 156: 974-987.

7. Gamsu G, Salmon Ch J, Warnock ML, Blanc PD. CT quantification of interstitial fibrosis in patients with asbestosis: a comparison of two methods. Am J Radiol 1995; 164: 63-68.

8. Staples C, Gamsu G, Ray CS, Webb WR. High resolution computed tomography and lung function in asbestosexposed workers with normal chest radiographs. $\mathrm{Am} \mathrm{Rev}$ Respir Dis 1989; 139: 1502-1508.

9. Miniati M, Filippi E, Falashi F, et al. Radiologic evaluation of emphysema in patients with chronic obstructive pulmonary disease. Am J Respir Crit Care Med 1995; 151: 1359-1367.

10. Viljanen AA, ed. Reference values for spirometric, pulmonary diffusing capacity and body plethysmographic studies. Scand J Clin Invest 1982; 42 (Suppl. 159): 1-50.

11. Sovijärvi ARA, Helistö P, Malmberg LP, et al. A new versatile PC-based lung sound analyzer with automatic crackle analysis (HeLSA); repeatability of spectral parameters and sound amplitude in healthy subjects. Technol Health Care 1998; 6: 11-22. 
12. Gavriely N, Cugell DW. Breath Sound Methodology. London, CRC Press, 1995.

13. Piirilä P, Sovijärvi ARA, Kaisla T, Rajala H-M, Katila T. Crackles in patients with fibrosing alveolitis, bronchiectasis, COPD and heart failure. Chest 1991; 99: 10761083.

14. Murphy RLH, Del Bono E, Davidson F. Validation of an automatic crackle (rale) counter. Am Rev Respir Dis 1989; 140: 1017-1020.

15. Hoevers J, Loudon RG. Measuring crackles. Chest 1990; 98: 1240-1243.

16. Vannuccini L, Rossi M, Pasquali G. A new method to detect crackles in respiratory sounds. Techno Health Care 1998; 6: 75-79.

17. Waris M, Helistö P, Haltsonen S, Saarinen A, Sovijärvi ARA. A new method for automatic wheeze detection. Techno Health Care 1998; 6: 33-40.

18. Malmberg LP, Sovijarvi ARA, Paajanen E, Piirilä P, Haahtela T, Katila T. Changes in frequency spectra of breath sounds during histamine challenge test in adult asthmatics and health control subjects. Chest 1994; 105: 122-132.

19. Lynch DA. CT for asbestosis: value and limitations. $A m J$ Radiol 1995; 164: 69-71.

20. Sakai R, Gamsu G, Im J-G, Ray CS. Pulmonary function abnormalities in patients with CT-determined emphysema. J Comput Assist Tomogr 1987; 11: 963-968.

21. Quanjer Ph. H, Tammeling GJ, Cotes JE, Pedersen OF, Peslin R, Yemault J-C. Lung, volumes and forced ventilatory flows. Eur Respir J 1993; 6: Suppl. 16, 5-40.
22. American Thoracic Society. Diagnosis of nonmalignant diseases related to asbestos. Am Rev Respir Dis 1986; 134: 363-368.

23. Al Jarad N, Davies SW, Logan-Sinclair R, Rudd RM. Lung crackle characteristics in patients with asbestosis, asbestos-related pleural disease and left ventricular failure using a time-expanded waveform analysis: a comparative study. Respir Med 1994; 88: 37-46.

24. Dosani R, Kraman SS. Lung sound intensity variability in normal men. Chest 1983; 83: 628-631.

25. American Thoracic Society. Standards for the diagnosis and care of patients with chronic obstructive pulmonary disease. Am Respir Crit Care Med 1995; 152: s77-s121.

26. Rice DA. Transmission of lung sounds. Sem Resp Med 1985; 6: 166-170.

27. Malmberg LP, Pesu L, Sovijärvi ARA. Significant differences in flow standardized breath sound spectra in patients with chronic obstructive pulmonary disease, stable asthma and healthy lungs. Thorax 1995; 50: 12851291.

28. Nairn JR, Turner-Warwick M. Breath sounds in emphysema. Brit J Dis Chest 1969; 63: 29-37.

29. Schreur HJW, Vandershoot J, van Klink HCJ, van Vollenhoven E, Dijkman JH. Lung sound intensity in patients with emphysema and in normal subjects at standardized airflows. Thorax 1992; 47: 674-679.

30. Malmberg LP, Sorva R, Sovijärvi ARA. Frequency distribution of breath sounds as an indicator of bronchoconstriction during histamine challenge test in asthmatic children. Pediatric Pulmonol 1994; 18: 170-177. 